\title{
CORROSION STUDY OF METALLIC BIOMATERIALS IN SIMULATED BODY FLUID
}

\author{
Hamid Reza Asgari Bidhendi , Majid Pouranvari \\ Materials and Metallurgical Engineering Department, Dezful Branch, Islamic \\ Azad University, Dezful, Iran
}

Received 27.12.2010

Accepted 21.02.2011

\begin{abstract}
Titanium alloys and stainless steel 316L are still the most widely used biomaterials for implants despite emerging new materials for this application. There is still some ambiguity in corrosion behavior of metals in simulated body fluid (SBF). This paper aims at investigating the corrosion behavior of commercially pure titanium (CP-Ti), Ti-6Al-4V and 316LVM stainless steel (316LVM) in SBF (Hank's solution) at $37^{\circ} \mathrm{C}$ using the cyclic polarization test. Corrosion behavior was described in terms of breakdown potential, the potential and rate of corrosion, localized corrosion resistance, and breakdown repassivation. The effects of anodizing on CP-Ti samples and the passivation on the 316LVM were studied in detail. It was shown that CP-Ti exhibited superior corrosion properties compared to Ti-6Al-4V and 316LVM.

Key words: Corrosion behavior, metallic biomaterials, Hank's solution, anodization, passivation
\end{abstract}

\section{Introduction}

The first requirement for any material to be placed in the human body is that it should be biocompatible and not cause any adverse reaction in the body [1]. The material must withstand the body environment and should not degrade to a point that it cannot function in the body as intended [2]. Corrosion of metal implants is critical because it can adversely affect the biocompatibility and mechanical properties. The materials used should not cause any adverse biological reaction in the body and, simultaneously, they must be stable retaining their functional properties. Corrosion and surface oxide film dissolution are the two mechanisms which introduce additional ions into the body [3]. Extensive release of ions from prosthesis can result in adverse biological reactions leading to mechanical failure of the device. For example, release of

* Corresponding author: Hamid Reza Asgari Bidhendi, hr.asgari@gmail.com 
nickel ion from 316LVM implant alloys may cause allergic effects in some patients [4]. That is why metals used in the human body must have a high corrosion resistance. Degradation of metals and alloys used as surgical implant orthopedic devices is usually a combination of electrochemical and mechanical effects. Modern day-life has resulted in the increased use of implants at a younger age, whereas the average life span has also been increased. Both these factors necessitated the use of materials with enhanced life and/or innovation of newer implant materials with prolonged life. Corrosion is the first consideration for a material of any type that is to be used in the body because metal ion release takes place mainly due to corrosion of surgical implants [5]. Therefore, various in vitro and in vivo tests have to be carried out in order to identify appropriate materials for use as surgical implants. It is desirable to keep the metal ion release to a minimum by the use of corrosion-resistant materials. Some effects of incompatible materials include interference with normal tissue growth near the implant, interference with systematic reactions of the body, and transport and deposition of metal ions at selective sites or organs may occur [6]. There is always a concern about the carcinogenic effects of foreign materials in the body both short- and long-term periods exceeding 20 years. Some individuals are sensitive to metals and some may develop metal sensitivity later after receiving an implant. The environment of the body is extremely well buffered so that the $\mathrm{pH}$ is maintained at around 7.4 at $37^{\circ} \mathrm{C}$. Two features control the severity of this environment. Firstly, the saline solution is an excellent electrolyte and facilitates the electrochemical mechanisms of corrosion and hydrolysis. Secondly, there are many molecular and cellular species in the tissues that have the ability to catalyze certain chemical reactions or rapidly destroy certain components identified as foreign [7]. Corrosion behavior of materials can be studied either in vivo or in vitro using artificial physiological fluids in which the oxygen content is controlled at a suitably low value at $37^{\circ} \mathrm{C}$. Hank's solution is an example of an artificial solution, which has been used over a period for corrosion testing in the laboratory [8].

The primary aim of the surface treatments is to enhance the protective passive film by changing its composition, structure and thickness, and/or by reducing weak points such as non-metallic inclusions [9]. Both passivation and anodizing have such effect on the surface layer forming a protective layer and preventing further corrosion. In order to understand anodizing and surface improvement of titanium [10,11] and passivation of various grades of stainless steels [9,12] on film formation and stability, different studies have been done. In the present investigation, a systematic study was carried out in order to understand the stability of various materials both for short- and long-term biomedical applications.

\section{Experimental procedure}

Substrates of commercially pure titanium (CP-Ti) grade 4 with the dimension of $6 \times 15 \times 3 \mathrm{~mm}$ were prepared. Stainless steel $316 \mathrm{LVM}(316 \mathrm{LVM})$ samples, and Ti-6Al-4V alloy samples were prepared with dimensions of $15 \times 10 \times 6 \mathrm{~mm}$. Afterwards, all samples were ground with SiC paper down to 1200 grit and cleaned with distilled water and ethylic alcohol.

For anodization of CP-Ti, a stainless steel 316L, $15 \times 30 \times 2 \mathrm{~mm}$ dimension cathode was used. Titanium samples were potentio-statically anodized in a glass cell at room 
temperature applying potentials ranging from 5 to $250 \mathrm{~V}$ in 0.5 and 1 molar phosphoric acid $\left(\mathrm{H}_{3} \mathrm{PO}_{4}\right)$ solution. Current densities for each set of anodizing tests were recorded. Anodizing time was ranged from 1 to 60 minutes. Passivation of 316LVM samples was carried out in a glass cell under conditions presented in Table 1. Then, the samples were washed, cleaned and dried with hot air after surface preparation and passivation.

Table 1. 316LVM stainless steel surface preparation and passivation conditions

\begin{tabular}{|c|c|}
\hline Surface Preparation & Passivation \\
\hline $\begin{array}{c}12.5 \mathrm{ml} \mathrm{HNO}_{3}+4 \mathrm{ml} \mathrm{HF}+33.5 \mathrm{ml} \mathrm{H}_{2} \mathrm{O} \text {, room } \\
\text { temperature, } 20 \mathrm{~min}\end{array}$ & $20 \% \mathrm{HNO}_{3}, 70^{\circ} \mathrm{C}, 30 \mathrm{~min}$ (no. 1) \\
\hline $\begin{array}{c}12.5 \mathrm{ml} \mathrm{HNO}_{3}+4 \mathrm{ml} \mathrm{HF}+33.5 \mathrm{ml} \mathrm{H}_{2} \mathrm{O} \text {, room } \\
\text { temperature, } 20 \mathrm{~min}\end{array}$ & $30 \% \mathrm{HNO}_{3}, 70^{\circ} \mathrm{C}, 30 \mathrm{~min}$ (no. 2) \\
\hline
\end{tabular}

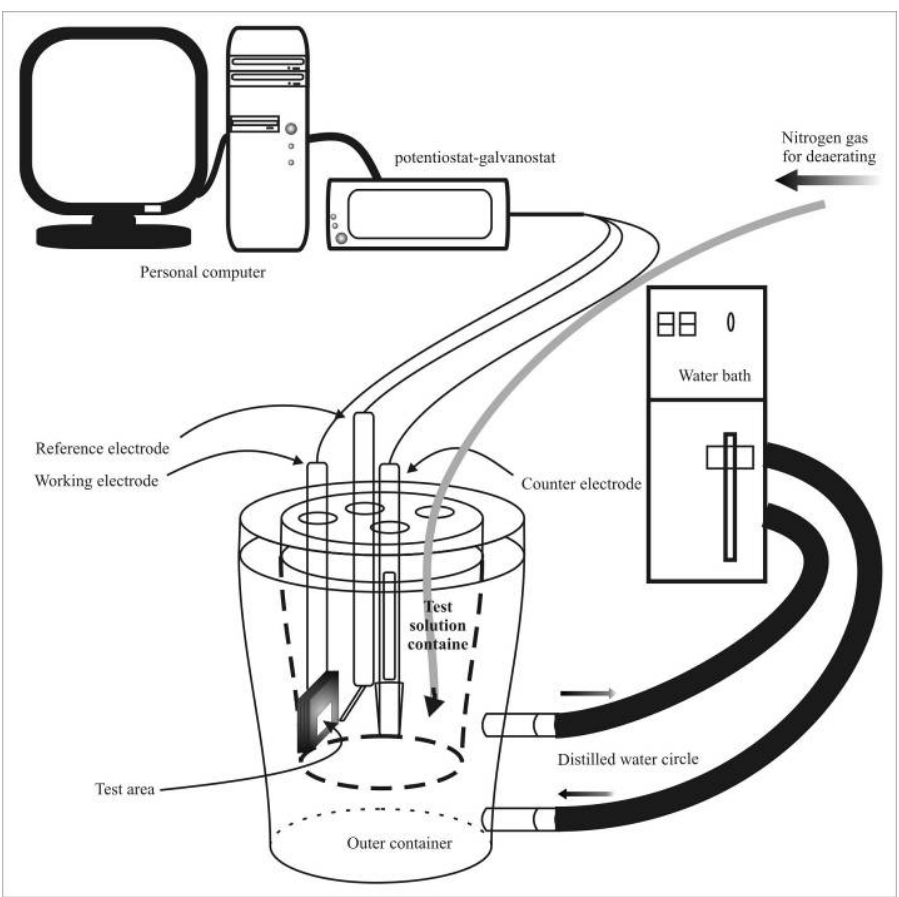

Figure 1. Schematic presentation of corrosion test assembly

Corrosion tests were carried out on CP-Ti, anodized Ti, Ti-6Al-4V alloy, 316LVM and passivated 316LVM samples. Hank's solution was prepared using high purity reagents. The chemical composition of the Hank's solution is shown in Table 2. The solutions were deaerated and maintained at $37 \pm 1{ }^{\circ} \mathrm{C}$. A schematic representation of corrosion test assembly is shown in Figure 1.

Cyclic polarization data were obtained in the form of potential vs. logarithmic current density curves in the range from -1100 to $3000 \mathrm{mV}$ using the $\mu$-AutoLab computer controlled potentiostat. The potential was increased at a rate of 5 milivolts per 
$\mathrm{min}$, starting from $-1100 \mathrm{mV}$ for $\mathrm{Ti}$ and from $-800 \mathrm{mV}$ for 316LVM. Electrode potentials were measured against a saturated calomel reference electrode. Before and after corrosion test sample's surface was examined using scanning electron microscope (SEM).

Table 2. Hank's solution chemical composition

\begin{tabular}{|c|c|c|c|c|c|}
\hline Component & $\mathrm{NaCl}$ & $\mathrm{KCl}$ & $\mathrm{CaCl}_{2}$ & $\mathrm{NaHCO}_{3}$ & $\mathrm{MgCl}_{2} \cdot 6 \mathrm{H}_{2} \mathrm{O}$ \\
\hline (g/L) & 8.00 & 0.40 & 0.14 & 0.35 & 0.60 \\
\hline Component & $\mathrm{MgSO}_{4} \cdot 7 \mathrm{H}_{2} \mathrm{O}$ & $\mathrm{Na}_{2} \mathrm{HPO}_{4}$ & $\mathrm{KH}_{2} \mathrm{PO}_{4}$ & Glucose. $2 \mathrm{H}_{2} \mathrm{O}$ & $\mathrm{pH}$ \\
\hline$(\mathrm{g} / \mathrm{L})$ & 0.06 & 0.06 & 0.60 & 1.0 & 6.8 \\
\hline
\end{tabular}

\section{Results and Discussion}

\section{Corrosion behavior}

Any metal intended for use as a biomaterial should exhibit excellent pitting and crevice corrosion resistance in body fluid. This can be determined by carrying out cyclic polarization experiments in Hank's solution at $37^{\circ} \mathrm{C}$. Table 3 illustrates corrosion current density, corrosion potential, breakdown potential and passive current density for CP-Ti, 316LVM and Ti-6Al-4V, as well as the best results obtained for anodized Ti and passivated 316LVM in de-aerated Hank's solution at $37^{\circ} \mathrm{C}$. The maximum corrosion rate was observed for the $316 \mathrm{LVM}$ followed by the Ti-6Al-4V alloy. The minimum corrosion rate was observed for the CP-Ti. Passivated 316LVM and anodized Ti have almost the same corrosion current densities. Protective films formed on the surface of the 316LVM and CP-Ti in corresponding surface treatments significantly improved $\mathrm{i}_{\text {corr }}$ and $\mathrm{E}_{\text {corr }}$. Corrosion potential value of CP-Ti and Ti-6Al-4V alloy was almost the same $(-470 \mathrm{mV})$ but higher than the value observed for 316LVM $(-630 \mathrm{mV})$. About $400 \mathrm{mV}$ improvement in $\mathrm{E}_{\text {corr }}$ was observed after passivation. Anodizing showed similar effect and improve $\mathrm{E}_{\text {corr }}$.

Table 3. Results of electrochemical corrosion tests in Hank's solution at $37^{\circ} \mathrm{C}$.

\begin{tabular}{|c|c|c|c|c|}
\hline Material & $\begin{array}{c}\mathrm{i}_{\text {corr }} \\
\left(\mathrm{A} / \mathrm{cm}^{2}\right)\end{array}$ & $\begin{array}{c}\mathrm{E}_{\text {corr }} \\
(\mathrm{V})\end{array}$ & $\begin{array}{c}\mathrm{i}_{\text {pass }} \\
\left(\mathrm{A} / \mathrm{cm}^{2}\right)\end{array}$ & $\begin{array}{c}\mathrm{E}_{\text {breakdown }} \\
(\mathrm{V})\end{array}$ \\
\hline Ti-6Al-4V & $5.72 \mathrm{E}-06$ & -0.47 & $2.1 \mathrm{E}-04$ & \\
\hline CP-Ti & $2.76 \mathrm{E}-06$ & -0.47 & $3.6 \mathrm{E}-04$ & \\
\hline anodized Ti sample no.1 & $2.13 \mathrm{E}-07$ & -0.10 & $3.9 \mathrm{E}-06$ & \\
\hline anodized Ti sample no. 2 & $7.71 \mathrm{E}-07$ & -0.31 & $6.6 \mathrm{E}-06$ & \\
\hline SS 316LVM & $2.14 \mathrm{E}-05$ & -0.63 & $3.2 \mathrm{E}-05$ & 0.55 \\
\hline passivated 316LVM sample no.1 & $2.45 \mathrm{E}-07$ & -0.21 & & 0.38 \\
\hline passivated 316LVM sample no. 2 & $3.94 \mathrm{E}-07$ & -0.20 & & 0.42 \\
\hline
\end{tabular}

As it is shown in Figure 2, no breakdown potential is observed for the CP-Ti and Ti-6Al-4V up to $3 \mathrm{~V}$ applied potential. $\mathrm{E}_{\text {breakdown }}$ for $316 \mathrm{LVM}$ was $550 \mathrm{mV}$. Passivated 316LVM exhibited lower breakdown potential, and therefore lower passivity range 
(difference between $\mathrm{E}_{\text {breakdown }}$ and $\mathrm{E}_{\text {pass }}$ ) than non-treated 316LVM sample. Moreover, when surface film breakdowns and localized corrosion takes place in a passivated stainless steel, repassivation of surface may be difficult due to the fact that a chromiumrich layer forms and the metal beneath surface depletes from chromium.

The cyclic polarization curves recorded for various materials in de-aerated Hank's solution at $37{ }^{\circ} \mathrm{C}$ are presented in Figure 2. A low passive current density, typical of a passive system, is observed at relatively low anodic potentials for all samples, but passive film breakdown and pitting attack, characterized by a sharp and steady increase in the anodic current, is observed in the potential region of $400 \mathrm{mV}$ for 316LVM samples [7]. The noises on the Ti-6Al-4V polarization curve could be attributed to initiation and repassivation of pits. No hystersis loop is observed for CP-Ti and Ti-6Al-4V alloy. In the case of 316LVM, the reverse scan takes an entirely different path when compared to the forward scan. This clearly indicates that the Ti alloys have excellent pitting and crevice corrosion resistance, while 316LVM is highly susceptible to pitting and crevice corrosion. Curves reported on CP-Ti and Ti-6Al-4V alloy samples indicate that Ti-6Al-4V behaves in a very similar way. The corrosion potential is similar for CP-Ti and Ti alloy samples. This can be ascribed to the fact that the passive films formed on these alloys are the same in nature, essentially consisting of $\mathrm{TiO}_{2}$ [8].

Ion release is an important factor in selection of a material for use in human body. Some ions like Ni can make allergic effect in human body and therefore more consideration should be taken for using 316L VM and Ni-Ti alloy. In long-exposure use of implants, whatever passive current density will be lower, less nickel ion release occurs. As shown in Figure 4, passive region in passivated 316LVM polarization curve is not broad. The passive current density is about 100 times lesser than non-treated sample. Passivated 316LVM even has less $\mathrm{i}_{\text {pass }}$ than CP-Ti and Ti-6Al-4V while there are differences about other corrosion parameters.

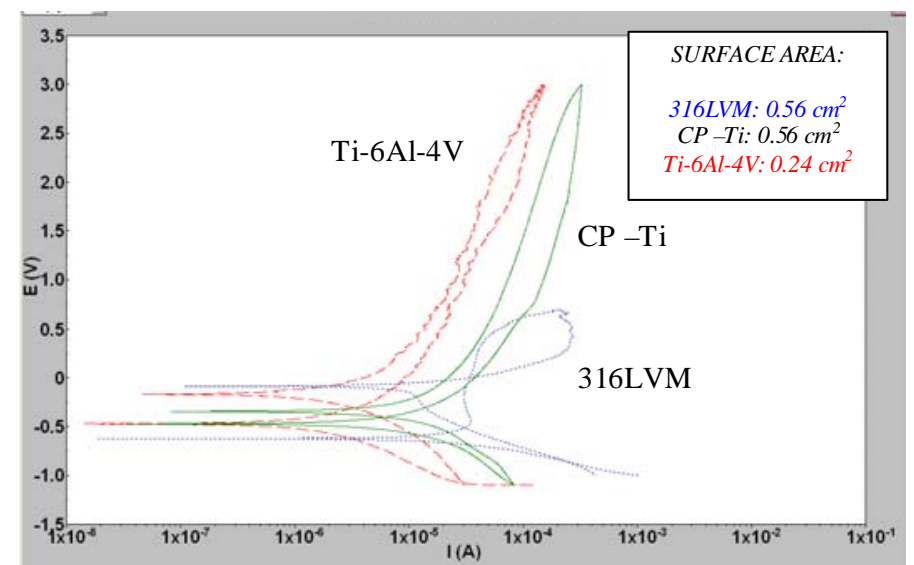

Figure 2. Cyclic polarization curves of the Ti-6Al-4V, CP Ti and 316LVM samples in Hank's solution at $37^{\circ} \mathrm{C}$

\section{Corrosion appearance}

SEM micrographs presented in Figure 3, show surface of investigated samples after their immersion in Hank's solution and cyclic polarization. As illustrated in this 
figure, ion complexes from Hank's solution (Table 2) and corrosion products are deposited on the surface. Distribution of these deposits corresponds to electrical charge distribution.

There are some weak points on the sample surface such as film rupture in upward branch of cyclic polarization test. In these points thickness of surface film is lower and consequently applied current can pass through the film easier than in other areas. Ion complexes pass the corrosive media and deposit on the broken sites of surface film when positive to negative potential sweep (downward branch of cyclic polarization curve) is applying.

Entire sample surfaces of CP-Ti and Ti-6Al-4V (Figures 3a and 3b) were covered by ion complexes; this means that all regions of surface have similar corrosion behavior and uniform corrosion occurred. From SEM micrograph, presented in Figure 3c, it is obvious that 316LVM is susceptible to pitting corrosion and higher corrosion current density is probably due to pit formation. It also can be seen that ion complexes were formed around the surface pits.
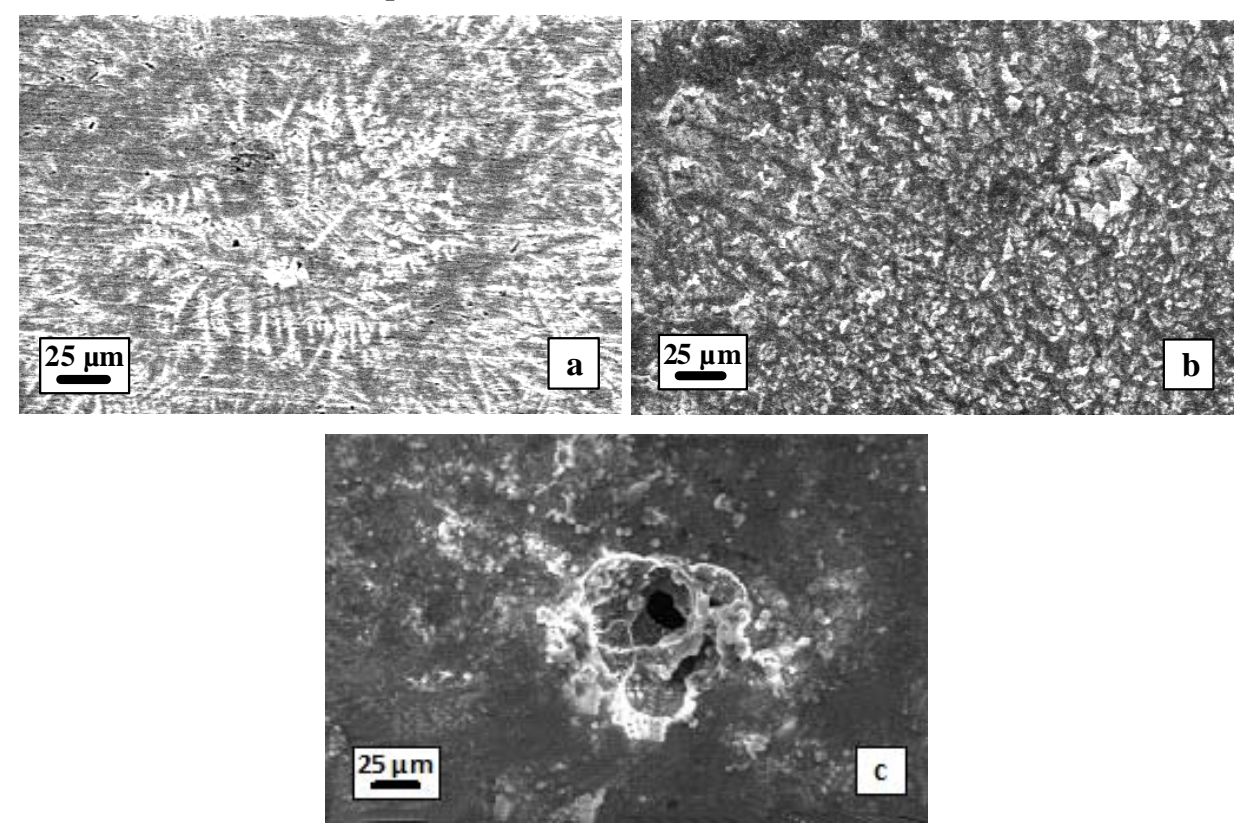

Figure 3. SEM micrograph showing corrosion products and ion complexes formed on the surface of , a) CP-Ti; b) Ti-6Al-4V; c) 316LVM after immersion in Hank's solution and cyclic polarization test

\section{Stainless steel passivation}

Based on the surface analysis, a three-layer model has been suggested for passive films formed on austenitic stainless steels in acidic solutions: the outer part of the film consists of a hydroxide film on the top of an oxide layer [13]. The oxy-hydroxide film is formed on the top of a Ni-enriched layer, the origin of which is the selective oxidation of Fe and $\mathrm{Cr}$ during anodic polarization [12]. 
Comparison between unpassivated and passivated 316LVM stainless steels is shown in Figure 4. As can be seen, the passivated sample has higher corrosion potential and exhibited an improved corrosion current density. Existing hysteresis loop in cyclic polarization curve shows that localized corrosion has been occurred. Passivation also prevents localized corrosion.

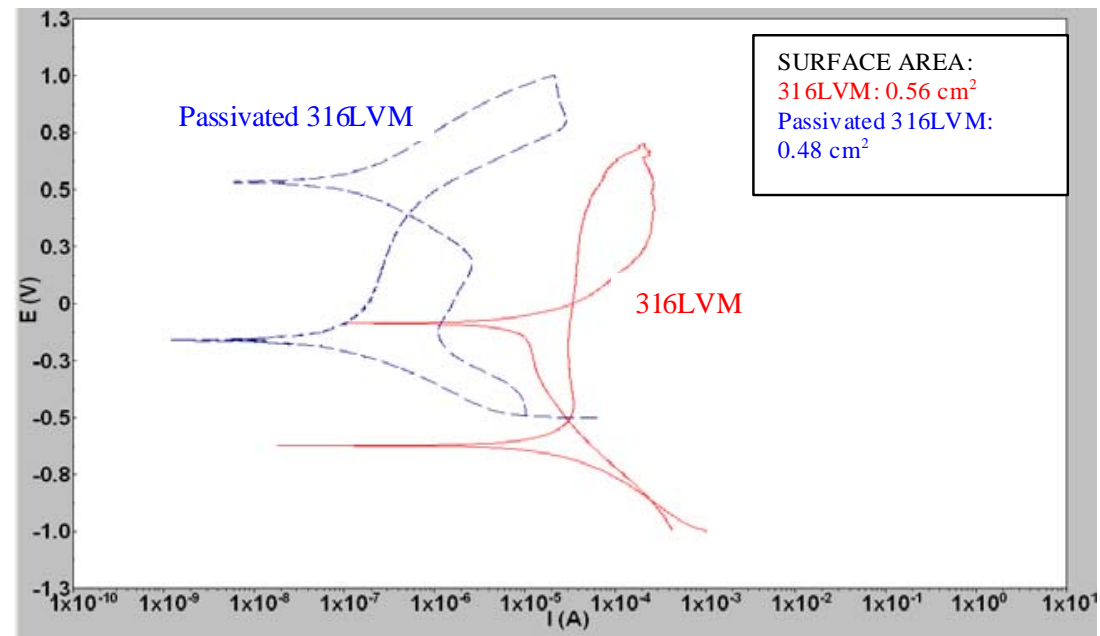

Figure 4. Cyclic polarization curves of the passivated and non-treated 316LVM samples in a Hank's solution at $37^{\circ} \mathrm{C}$

In the case of passivated 316LVM, CP-Ti and Ti-6Al-4V samples film breakdown could not be registered.

Some researchers [12] suggested that the improved corrosion behavior of 316LVM can be attributed to $\mathrm{Cr}$ and other elements contributing to the formation of passive film. Others [13] have proposed that immersion in nitric acid removes sulfide inclusions of the stainless steel thus eliminating preferential sites for corrosion attack.

The practical use of the nitric acid treatment might be limited if the treatment leads to formation of a Cr-depleted zone underneath the passive film, since damage of the passive film leads to Cr-depleted zone exposure to the environment. The atomic ratio $\mathrm{Cr} /(\mathrm{Cr}+\mathrm{Fe}+\mathrm{Ni})$ under the passive film was found to vary between 20 to $25 \%$ in the passivation treated specimens which is the same or somewhat higher than in the bulk (20\%). On the other hand, Ni-enrichment was detected and Fe was found to be depleted [9]. The results suggest that Fe is selectively dissolved during the passivation treatment and $\mathrm{Cr}$ does not seem to be depleted underneath the passive film [9].

\section{Titanium anodizing}

Anodizing with different conditions produces porous film but some morphological differences can be observed. Anodization in low voltage results in thin film, however as the voltage increases, the film breaks down locally and porous regions are formed. This behavior can be seen in voltages over than $20 \mathrm{~V}$. The porosity and the pore size increase with the increasing voltage [10]. To produce a thick and protective oxide film on CP-Ti the formed oxide should not either corrode in the anodizing media 
or the forming rate of oxide must be more than the rate of film dissolution in the anodizing electrolyte. At low potentials, from 1 to $130 \mathrm{~V}$, it is possible to obtain a 3-100 $\mathrm{nm}$ thick, smooth and amorphous oxide layer. On the contrary, high potentials (100-250 V) combined with high current densities lead to the formation of few tents to hundreds micrometers thick oxide, as it is also reported by some researchers [11].

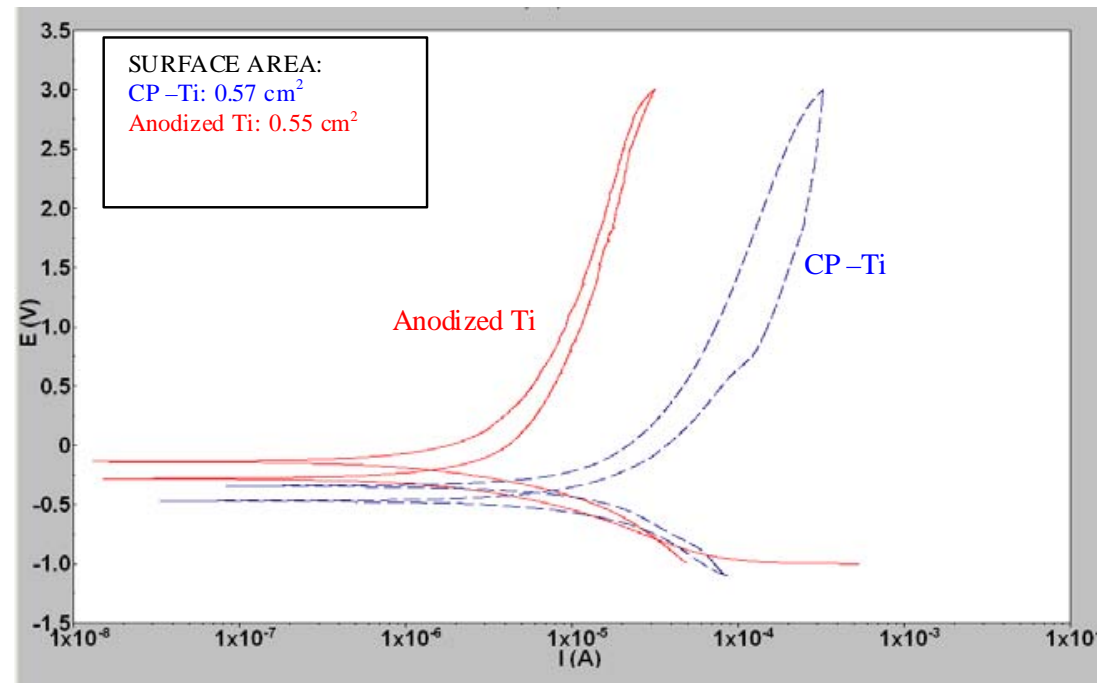

Figure 5. Cyclic polarization curves of the anodized and non-treated CP Ti samples in Hank's solution at $37^{\circ} \mathrm{C}$

As can be seen from Figure 5, anodization has significant effect on the passive current density (even decrease it 100 times). This also has a positive effect on the ion release in long exposure time [14]. $\mathrm{E}_{\text {corr }}$ and $\mathrm{i}_{\text {corr }}$ are also improved after Ti anodization in $\mathrm{H}_{3} \mathrm{PO}_{4}$. The $\mathrm{TiO}_{2}$ film produced from anodizing consists of two layers: a thin, compact and protective layer sticking directly on metal surface, and a porous layer on the top of it.

As anodizing was carried out in low concentrated phosphoric acid solution (0.01 $\mathrm{M}$ ), very fine surface structure on Ti was produced. A low concentration corresponds to a low electrical conductivity of the electrolyte, which increases the voltage drop across the electrolyte and consequently leads to smaller breakdown sites [10]. Higher phosphoric acid concentrations produce more rough oxide film with large breakdown sites evident in some surface regions. At high potentials, surface is smoother, but porosity is more pronounced (Figure 6). 


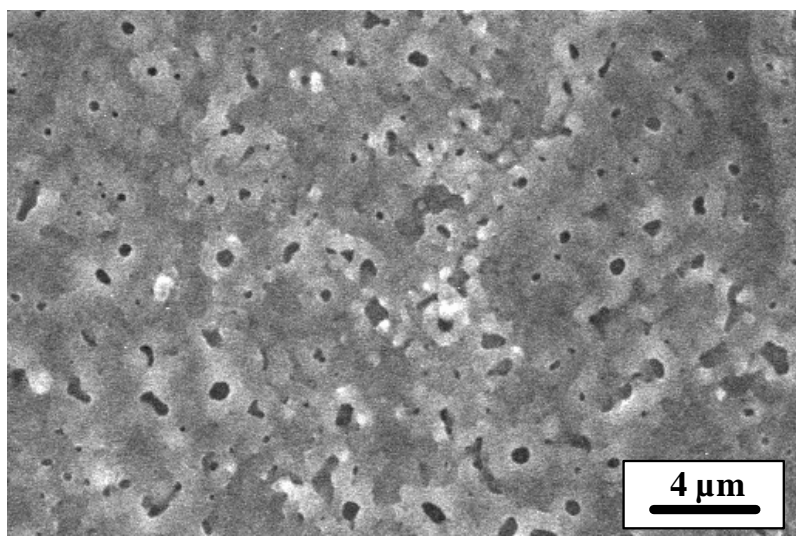

Figure 6. SEM micrograph from CP-Ti surface anodized in 0.5 molar $\mathrm{H}_{3} \mathrm{PO}_{4}$, for 30 min and applied voltage $200 \mathrm{~V}$

\section{Conclusions}

a) CP-Ti used in this study, had the lowest corrosion rate and corrosion potential, whereas 316LVM showed lower passive current density than CP-Ti and Ti-6Al-4V.

b) $316 \mathrm{LVM}$ is susceptible to localized corrosion during long term exposure.

c) Anodization affected all corrosion parameters of CP-Ti improving them considerably.

d) Passivation had significant influence on corrosion behavior of 316LVM and makes it more reliable for use in human body.

e) Based on this research, anodized CP-Ti is the best candidate for use in human body due to its lower corrosion rate and higher corrosion potential coupled with the absence of localized corrosion.

\section{References}

[1] A.C. Fraker, Corrosion, ASM Handbook, ASM International, Vol. 13, pp. 13241335, 1992.

[2] M. Niinomi, Mat. Sci. Eng. A243 (1998) 231-236.

[3] J. R. Davis, Handbook of materials for medical devices, ASM International, 2003

[4] I. Gurappa, Mat. Charact. 49 (2002) 73-79.

[5] J.E.G. Gonzalez, J.C. Mirza-Rosca, J. Electroanalytical Chem. 471 (1999) 109115.

[6] M.A. Khan, R.L. Williams, D.F. Williams, Biomaterials 20 (1999) 765-772.

[7] M. Aziz-Kerrzo, K.G. Conroy, A.M. Fenelon, S.T. Farrell, C.B. Breslin, ibid. 22 (2001) 1531-1539.

[8] S.L. de Assis, S. Wolynec, I. Costa, Electrochimica Acta 35 (2005) 28-36.

[9] D. Wallinder, J. Pan, C. Leygraf, A. Delblanc-Bauer, Corrosion Sci. 30 (1999) 164-178. 
[10] K. Neide, K. Kuromoto, R.A. Simao, G.A. Soares, Mat. Charact. 52 (2006) 7684.

[11] M.V. Diamanti, M.P. Pedeferri, Corrosion Sci. 154 (2006) 76-85

[12] O.A. Olsson, D. Landolt, Electrochimica Acta 48 (2003) 1093-1104.

[13] P. Stefanov, D. Stoychev, M. Stoycheva, T. Marinova, Mat. Chem. Phys. 65 (2000) 212-215.

[14] H.R.A. Bidhendi, M.Sc. Thesis, Shiraz University, Iran, 2007. 